\title{
Evidence that protein antigen b of Mycobacterium tuberculosis is involved in phosphate metabolism
}

\author{
Åse Bengård ANdersen, ${ }^{1 *}$ Lene LJUngQvist ${ }^{1}$ and MARIANNe Olsen ${ }^{2}$ \\ ${ }^{1}$ The Mycobacteria Department, Statens Seruminstitut, 80 Amager Boulevard, DK-2300 Copenhagen S, Denmark \\ ${ }^{2}$ The Protein Laboratory, University of Copenhagen, Copenhagen, Denmark
}

Protein antigen b (Pab) of Mycobacterium tuberculosis has previously attracted interest because of its immunological and diagnostic relevance. In this study we present evidence that Pab possesses a signal sequence and is secreted from the cytoplasm of $M$. tuberculosis. The synthesis of Pab is enhanced under phosphate starvation indicating that the protein is involved in phosphate metabolism in M. tuberculosis.

\section{Introduction}

Mycobacterium tuberculosis is the causative agent of tuberculosis - a serious infectious disease still far from being eradicated, especially in developing countries. However, little is known about the nature of the virulence of $\boldsymbol{M}$. tuberculosis and other mycobacterial pathogenic species. Many mycobacterial proteins are known to be immunologically reactive; here we study the biological function and possible role in pathogenicity of one of them.

We have previously isolated the gene encoding protein antigen $\mathrm{b}(\mathrm{Pab} ; 38 \mathrm{kDa})$ from $M$. tuberculosis, because of the immunological and diagnostic relevance of this protein (Andersen \& Hansen, 1989). The protein possesses species specific B-cell epitopes defined by monoclonal antibodies (mAbs) (Andersen $e t$ al., 1986). T-Lymphocytes isolated from immunized mice, guinea pigs or humans proliferate when cultured in the presence of purified Pab (Kadival et al., 1987; Young et al., 1986; Worsaae et al., 1987). A high proportion of humans suffering from active tuberculosis - especially if they are of the HLA type DR2 - have been shown to develop antibodies towards Pab (Bothamley et al., 1989).

In this study we have sought evidence that $\mathrm{Pab}$ is secreted from the cytoplasm of $\boldsymbol{M}$. tuberculosis and that the protein is involved in phosphate metabolism.

Abbreviations: $\mathrm{CF}$, culture filtrate; $\mathrm{mAb}$, monoclonal antibody; Paa, protein antigen $\mathrm{a}$, the ' $65 \mathrm{kDa}$ protein'; $\mathrm{Pab}$, protein antigen $\mathrm{b}$, a $38 \mathrm{kDa}$ protein.

The amino acid sequence data reported in this paper have been submitted to GenBank and have been assigned the accession number M30046.

\section{Methods}

Bacterial strains. The strain Mycobacterium tuberculosis H37Rv used in this study originates from a series of mycobacteria submitted by the International Working Group on Mycobacterial Taxonomy, 1966.

$m A b s$. The mAbs HYT 28, HAT2 and HBT 12, all of which bind Pab, were produced as described previously (Ljungqvist et al., 1988; Schou et al., 1985). The mAb HAT 5 was obtained from BALB/c mice immunized with Escherichia coli Y 1089 (Young \& Davis, 1983). The supernatants from growing hybridomas were tested for reactivity towards concentrated culture filtrate (CF) of M. tuberculosis H37Rv in an enzyme-linked immunosorbent assay (ELISA). The clone HAT 5 produced $\mathrm{mAbs}$ that bound to a protein of molecular mass $65 \mathrm{kDa}$. That this protein is the so-called $65 \mathrm{kDa}$ protein (in our laboratory designated protein antigen a, Paa) was verified by experiments in which HAT 5 bound a recombinant version of the molecule, MbaA (kindly provided by J. van Embden, Bilthoven, the Netherlands), and the fusion protein produced by the $\lambda$ phage $Y 3143$ (Husson \& Young, 1987) (obtained through the World Health Organization Immunology of Tuberculosis Programme, reference number WHO 0071.wibr) which is known to encode Paa.

Affinity purification of Pab. Protein A-purified HBT 12 immunoglobulins were coupled to Mini-Leak vinylsulphone-agarose (Kem-entec). CF of $M$. tuberculosis $\mathrm{H} 37 \mathrm{Rv}$ was prepared as described previously (Andersen et al., 1986). Briefly, M. tuberculosis H37Rv was grown as a surface pellicle on Sauton's medium in Fernbach flasks. The bacteria were separated from the growth medium, usually after 5 weeks, by filtration. Antigenic material was recovered from the medium by ammonium sulphate precipitation. Samples of the CF were applied to the column. Bound material was eluted by lowering the $\mathrm{pH}$ to 2.8 with $0.1 \mathrm{M}$-glycine/ $\mathrm{HCl}$ buffer. After desorption the $\mathrm{pH}$ of the eluate was immediately adjusted to 8 by titration with $1 \mathrm{M}-\mathrm{Tris} / \mathrm{HCl}, \mathrm{pH} 8.6$. The eluted material was dialysed against redistilled water and small samples were frozen at $-20^{\circ} \mathrm{C}$ until use.

The purity of the product was analysed by Western blotting. Probing with hyperimmune polyclonal rabbit anti- $M$. tuberculosis immunoglobulins gave rise to one band only at the expected position corresponding to a molecular mass of $38 \mathrm{kDa}$. 
Amino acid sequence analysis. Automatic microsequence analysis was done on a gas-phase sequencer (Applied Biosystems 470A). The phenylthiohydantoin derivatives were analysed on-line (Applied Biosystems 120A). All reagents were obtained from Applied Biosystems. Sequencing was done twice with the same result.

Phosphate starvation experiments. M. tuberculosis H37Rv was inoculated into Dubos medium in Erlenmeyer flasks and grown at $37^{\circ} \mathrm{C}$ while rotating. Dubos medium contains the detergent Tween 80 to allow dispersed growth. Two samples of $40 \mathrm{ml}$ were harvested by centrifugation at $6000 \mathrm{~g}$ when the culture had reached an $\mathrm{OD}_{460}$ of 0.3 . The bacteria were suspended in either $50 \mathrm{ml}$ Dubos medium or $50 \mathrm{ml}$ Dubos medium prepared without phosphate. This medium was buffered with Tris/ $\mathrm{HCl}, \mathrm{pH} 7 \cdot 6$, to a final concentration of $10 \mathrm{~mm}$. Growth was continued for $24 \mathrm{~h}$. The growth of the bacteria in Dubos medium with phosphate exceeded the growth of those in the medium without phosphate as determined by $\mathrm{OD}_{460}$ measurements. The culture with phosphate was diluted with medium until identical $\mathrm{OD}_{460}$ values were obtained. A sample $(40 \mathrm{ml})$ of each culture was harvested and suspended in sample buffer ( $62 \mathrm{~mm}-\mathrm{Tris}, \mathrm{pH} 6.8,2 \%$, w/v, sodium dodecyl sulphate, $0.7 \mathrm{M}$-2-mercaptoethanol), boiled for $15 \mathrm{~min}$ and subjected to sonication.

Samples of the disintegrated bacteria were run on a $10 \%(w / v)$ polyacrylamide gel and transferred onto nitrocellulose sheets (Schleicher and Schuell) by electroblotting in a semi-dry system, essentially as described by Kyhse-Andersen (1984). The nitrocellulose sheets were incubated for $2 \mathrm{~h}$ at room temperature with a mixture of the anti-Pab mAbs HYT 28, HBT 12 and HAT 2, and the anti-Paa mAb HAT 5 , diluted in phosphate-buffered saline $(0.5 \mathrm{M}-\mathrm{NaCl}, 0.15 \mathrm{M}$ $\mathrm{Na}_{3} \mathrm{PO}_{4}, \mathrm{pH} 7 \cdot 2$ ) with $0.05 \%$ Tween 20 (PBS/Tween). The nitrocellulose sheets were washed with PBS/Tween three times for $10 \mathrm{~min}$. Bound $\mathrm{mAbs}$ were detected by ${ }^{35} \mathrm{~S}$-labelled anti-mouse immunoglobulins from sheep (Amersham). The specific activity was 200 to $700 \mathrm{Ci}$ (mmol immunoglobulin) ${ }^{-1}[7.4$ to $25.9 \mathrm{TBq}$ (mmol immunoglobulin) ${ }^{-1}$. The labelled immunoglobulins were diluted in PBS/Tween to $0.5 \mu \mathrm{Ci} \mathrm{ml}^{-1}\left(1.85 \times 10^{4} \mathrm{~Bq} \mathrm{ml}^{-1}\right)$. The labelled anti-mouse immunoglobulins were incubated with the nitrocellulose blots for either $1 \mathrm{~h}$ at room temperature or overnight at $4{ }^{\circ} \mathrm{C}$. Unbound immunoglobulins were removed by three washes with PBS/Tween. The nitrocellulose blots were allowed to air-dry before autoradiography (Hyperfilm-MP, Amersham). The films were usually exposed for $4 \mathrm{~d}$.

\section{Results and Discussion}

We have recently published the nucleic acid sequence of the gene encoding $\mathrm{Pab}$ of $\boldsymbol{M}$. tuberculosis (Andersen \& Hansen, 1989). The deduced amino acid sequence exhibited $30 \%$ homology to PstS (also designated PhoS) of $E$. coli. PstS is a phosphate-binding protein which is localized in the periplasm and involved in the transport of phosphate, especially under phosphate-limited conditions (Magota et al., 1984; Surin et al., 1984). PstS is synthesized in a precursor form with a 25 amino acid residue signal sequence which is cleaved off when the protein reaches the periplasmic space (Magota et al., 1984; Surin et al., 1984). The $\mathrm{N}$-terminal sequence of $\mathrm{Pab}$ deduced from its nucleic acid sequence is that of a typical signal sequence: two charged amino acid residues, a lysine and an arginine residue, followed by a stretch of 22 non-polar residues. To test this prediction we affinity purified native Pab from CF of $M$. tuberculosis H37Rv, and determined the amino acid sequence of the mature

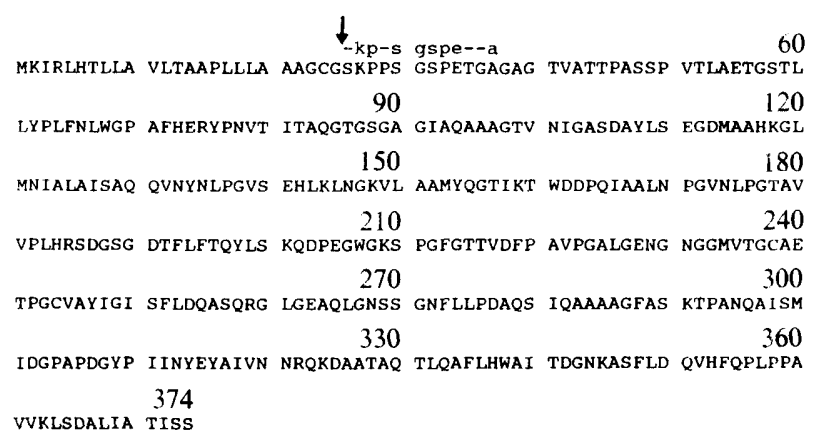

Fig. 1. Amino acid sequence of Pab, given in conventional one letter symbols. On the upper line in lower case letters is shown the sequence obtained by amino acid sequencing of native Pab. The lower line gives the sequence deduced from the nucleic acid sequence. The arrow indicates the signal peptidase cleavage site.

protein as described in Methods. The result is shown in Fig. 1. The sequence derived by amino acid sequencing of the $\mathrm{N}$-terminal residues of the native $\mathrm{Pab}$ matches the sequence deduced from the nucleic acid sequence with the first amino acid residue probably being the serine at position 26 . The cleavage site would therefore be located at the carboxy-terminal side of the glycine residue at position 25. According to Watson (1984), $88 \%$ of 40 wellcharacterized prokaryotic signal sequences end with either an alanine or a glycine residue. According to Oliver (1985) a conserved sequence, $A-X-B$, is found adjacent to most cleavage sites, where $B$ is position - 1 relative to the cleavage site and $A$ is position -3 . B is preferentially a glycine, alanine or serine residue and $A$ is either one of the same three amino acids or leucine, valine or isoleucine. $X$ can be any amino acid. The cleavage site of Pab fits these described features with the sequence glycine-cysteine-glycine.

Three proteins of $M$. bovis BCG have signal peptide sequences consistent with their being secreted from the cytoplasm. They are the alpha antigen (Matsuo et al., 1988), MPB70 (Teresaka et al., 1989) and MPB64 (Yamaguchi et al., 1989). Also, sequence data on the $28 \mathrm{kDa}$ protein from $M$. leprae suggests that this protein is localized in the plasma membrane or cell wall (Cherayil \& Young, 1988).

Pab is similar to PstS of $E$. coli in its sequence homology and the presence of a signal sequence. Thus, we wanted to study whether the functions of the two proteins were also related.

We demonstrated that the synthesis of Pab is induced (or derepressed) under phosphate starvation which may indicate that Pab plays a role in phosphate metabolism. $M$. tuberculosis H37Rv was grown in Dubos medium, and transferred to fresh medium with or without phosphate in which growth was continued for $24 \mathrm{~h}$.

The amount of Pab synthesized with or without phosphate was analysed by an immunodetection tech- 


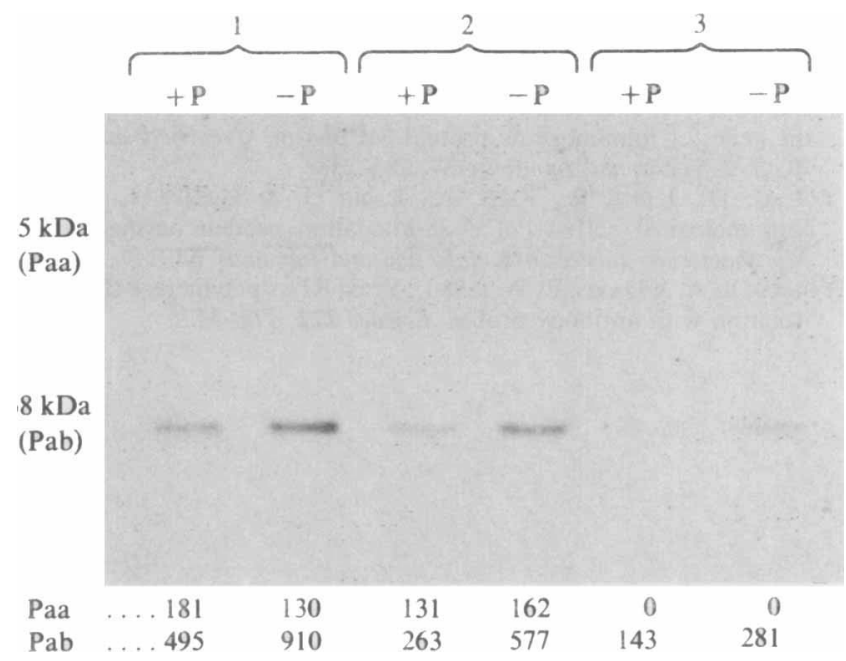

Fig. 2. Autoradiography of Western blot analyses of $M$. tuberculosis H37Rv grown with $(+P)$ or without $(-P)$ phosphate. Lanes 2 and 3 contain serial twofoid dilutions of the samples in lane 1. The samples were separated on a $10 \%$ polyacrylamide gel and transferred onto a sheet of nitrocellulose, which was subsequently incubated with a mixture of anti-Pab mAbs HYT 28, HAT 2 and HBT 12 and the antiPaa mAb HAT 5 . When the bands were excised from the nitrocellulose sheet corresponding to the autoradiogram, and their radioactivity determined by scintillation counting, c.p.m. values minus background (with background, 185 c.p.m., obtained from areas of the sheet where no bands could be seen) were as shown. Similar results were obtained in three independent experiments.

nique and compared with the synthesis of Paa - the 65 kDa protein' - which served as an internal standard in this experiment. $M$. tuberculosis Paa exhibits significant homology to the heat shock protein GroEL of $E$. coli and is not involved in phosphate metabolism (Shinnick et al., 1988). Fig. 2 shows that the production of $\mathrm{Pab}$ is greater under phosphate starvation while the production of Paa is unaltered. The enhanced synthesis of Pab cannot, therefore, be attributed to a general stress response.

PstS of $E$. coli exerts its function in the periplasm. There are no reports of a true periplasmic space in mycobacteria. The appearance of $\mathrm{Pab}$ in $\mathrm{CF}$ is not sufficient evidence for Pab being an excreted, extracellular protein as during the culture period ( 5 weeks), some bacteria will probably have lysed. If the function of $\mathrm{Pab}$ is to ensure phosphate uptake during phosphate-limited conditions, we believe that the protein has to remain attached to the bacterium once transported across the cell membrane, either directly anchored in the cell membrane or somehow associated with the cell wall. Further studies are needed to reveal the exact location of the molecule.

In conclusion, we have established the $\mathrm{N}$-terminal amino acid sequence of $\mathrm{Pab}$. This sequence confirms the amino acid sequence deduced from the nucleic acid sequence. A precursor form of the molecule with a signal sequence must exist. The synthesis of $\mathrm{Pab}$ is induced under phosphate starvation indicating that the protein is involved in phosphate metabolism in $M$. tuberculosis.

We wish to thank Vibeke Larsen, Iben Nielsen and Tove Simonsen for excellent technical assistance and Grethe Jensen for typing the manuscript. This work has received support from the Research Centre for Medical Biotechnology in Denmark.

\section{References}

Andersen, A. B., Yuan, Z. L., Hasløv, K., Vergmann, B. \& BENNEDSEN, J. (1986). Interspecies reactivity of five monoclonal antibodies to Mycobacterium tuberculosis as examined by immunoblotting and enzyme-linked immunosorbent assay. Journal of Clinical Microbiology 23, 446-451.

ANDERSEN, A. B. \& HANSEN, E. B. (1989). Structure and mapping of antigenic domains of protein antigen $b$, a 38,000-molecular-weight protein of Mycobacterium tuberculosis. Infection and Immunity 57, 2481-2488.

Bothamley, G. H.. Beck, J. S., Schreuder, G. M. T., D'Amaro, J., De VRIES, R. R. P., KaRdito, T. \& IVANYI, J. (1989). Association of tuberculosis and Mycobacterium tuberculosis-specific antibody levels with HLA. Journal of Infectious Diseases 159, 549-555.

Cherayil, B. J. \& Young, R. A. (1988). A $28-\mathrm{kDa}$ protein from Mycobacterium leprae is a target of the antibody response in lepromatous leprosy. Journal of Immunology 141, 4370-4375.

Husson, R. N. \& Young, R. A. (1987). Genes for the major protein antigens of Mycobacterium tuberculosis: the etiologic agents of tuberculosis and leprosy share an immunodominant antigen. Proceedings of the National Academy of Sciences of the United States of America 84, 1679-1683.

Kadival, G. V., Chaparas, S. D. \& Hussong, D. (1987). Characterization of serologic and cell-mediated reactivity of a $38-\mathrm{kDa}$ antigen isolated from Mycobacterium tuberculosis. Journal of Immunology 139, 2447-2451.

KYHSE-ANDERSEN, J. (1984). Electroblotting of multiple gels: a simple apparatus without buffer tank for rapid transfer of proteins from polyacrylamide to nitrocellulose. Journal of Biochemical and Biophysical Methods 10, 203-209.

LJUNGovist, L., WorsaAe, A. \& Heron, 1. (1988). Antibody responses against Mycobacterium tuberculosis in 11 strains of inbred mice: novel monoclonal antibody specificities generated by fusions, using spleens from BALB. B10 and CBA/J mice. Infection and Immunity 56, 1994-1998.

Magota, K., Otsuin, N., Miki, T., Horiuchi, T., Tsunasawa, S. Kondo, J., Sakiyama, F., Amemura, M., Morita, T., Shinagawa, H. \& NAKATA, A. (1984). Nucleotide sequence of the phoS gene, the structural gene for the phosphate-binding protein of Escherichia coli. Journal of Bacteriology 157, 909-917.

Matsuo, K., Yamaguchi, R., Yamazaki, A., Tasaka, H. \& Yamada, T. (1988). Cloning and expression of the Mycobacterium bovis BCG gene for extracellular alpha antigen. Journal of Bacteriology 170, 3847-3854.

Oliver, D. (1985). Protein secretion in Escherichia coli. Annual Review of Microbiology 39, 615-648.

Schou, C., Yuan, Z.-L., ANDERsen, Å. B. \& Bennedsen, J. (1985). Production and partial characterization of monoclonal hybridoma antibodies to Mycobacterium tuberculosis. Acta Pathologica Microbiologica et Immunologica Scandinavica Section C Immunology 93, 265-272.

Shinnick, T. M., Vodkin, M. H. \& Williams, J. C. (1988). The Mycobacterium tuberculosis 65-kilo-dalton antigen is a heat shock protein which corresponds to common antigen and to the Escherichia coli groEL protein. Infection and Immunity 56, 446-451. 
Surin, B. P., Jans, D. A., Fimmel, A. L., Shaw, D. C., Cox, G. B. \& ROSENBERG, H. (1984). Structural gene for the phosphate-repressible phosphate-binding protein of Escherichia coli has its own promoter: complete nucleotide sequence of the phoS gene. Journal of Bacteriology 157, 772-778.

Terasaka, K., Yamaguchi, R., Matsuo, K., Yamazaki, A., Nagal, S. \& YAMADA, T. (1989). Complete nucleotide sequence of immunogenic protein MPB70 from Mycobacterium bovis BCG. FEMS Microbiology Letters 58, 273-276.

WATSON, M. E. E. (1984). Compilation of published signal sequences. Nucleic Acids Research 12, 5145-5164.

Worsaae, A., LuUngqvist, L., Hasløv, K., Heron, I. \& BenNedsen, J. (1987). Allergenic and blastogenic reactivity of three antigens from Mycobacterium tuberculosis in sensitized guinea pigs. Infection and Immunity 55, 2922-2927.

Yamaguchi, R., Matsuo, K., Yamazaki, A., Abe, C., Nagal, S. TERASAKA, K. \& YAMADA, T. (1989). Cloning and characterization of the gene for immunogenic protein MPB64 of Mycobacterium bovis BCG. Infection and Immunity 57, 283-288.

Young, D., Kent, L., Rees, A., LAmb, J. \& IVANyi, J. (1986). Immunological activity of a 38-kilodalton protein purified from Mycobacterium tuberculosis. Infection and Immunity 54, 177-183.

YounG, R. A. \& DAvIs, R. W. (1983). Yeast RNA polymerase II genes: isolation with antibody probes. Science 222, 778-782. 